\title{
The Effect of Electrolyte pH on the Ni-Co Mixed Oxides Coatings Produced from Citrate Baths
}

\author{
Julyana Ribeiro Garcia ${ }^{,}$Dalva Cristina Baptista do Lagoa ${ }^{a}$ Deborah Vargas \\ Cesar $^{b}$, Lilian Ferreira de Senna ${ }^{a *}$ \\ ${ }^{a}$ Laboratório de Corrosão e Eletroquímica - LEC, Programa de Engenharia Química - PPG-EQ; \\ Universidade do Estado do Rio de Janeiro - UERJ, Rua São Francisco Xavier, 524, Pavilhão Haroldo \\ Lisboa da Cunha, S. 427, Maracanã. 20550-013, Rio de Janeiro, RJ, Brazil. \\ ${ }^{b}$ Laboratório de Materiais para Engenharia Química - LabMEQ, Programa de Engenharia Química - \\ PPG-EQ; Universidade do Estado do Rio de Janeiro - UERJ, Rua São Francisco Xavier, 524, Pavilhão \\ Haroldo Lisboa da Cunha, S. 606, Maracanã. 20550-013, Rio de Janeiro, RJ, Brazil.
}

Received: October 30, 2017; Accepted: November 27, 2017

\begin{abstract}
In this work, Ni-Co oxides coatings were produced using electrochemical techniques (chronopotentiometry and/or linear voltammetry) and solutions containing $\mathrm{Ni}^{2+}$ and $\mathrm{Co}^{2+}$ ions in the molar ratio 1:2, sodium citrate as the ligand, and different $\mathrm{pH}$ values (7.5 and 10.5). Energy dispersive spectrometry (EDS), scanning electron microscopy (SEM), Raman spectroscopy (LRS) and electrochemical impedance spectroscopy (EIS) were used to characterize these coatings. The results showed that both $\mathrm{pH}$ values favored the production of Ni-Co oxide phases, independent of the electrochemical technique used. The EDS analysis indicated that it was possible to produce of oxides coating presenting different $\mathrm{Ni}$ :Co ratios using electrodeposition process. However, the morphology, the microstructure and the electrocatalytic ability of the coatings depended on both the $\mathrm{pH}$ and on the electrochemical technique used to produce them. The coatings produced using $\mathrm{pH} 10.5$ were suitable to be used as electrocatalysts for the oxygen evolution reaction (OER).
\end{abstract}

Keywords: $\mathrm{Ni}$-Co oxides, nickel cobaltite, chronopotentiometry, linear voltammetry, electrotalysis.

\section{Introduction}

Electrochemical deposition techniques allow the production of functional metallic, ceramics or composites coatings of excellent quality. By using these techniques, it is possible to produce very thin and homogeneous films with specific chemical and morphological properties. It is also possible to control the deposited materials process efficiently, depending on the adjustment of experimental parameters such as $\mathrm{pH}$, solution composition, temperature, applied potential, polarization time and electrode substrate. Moreover, there is a great availability of the equipments used to obtain these coatings ${ }^{1-3}$.

Thin nanostructured oxide layers produced by electrodeposition have been used as appropriate materials for different electrochemical processes, ranging from anticorrosive to electrocatalytic properties ${ }^{4-9}$. Among the electrocatalytic coatings, there is a great interest in those useful to enhance the $\mathrm{O}_{2}$ and $\mathrm{H}_{2}$ evolution reactions (respectively, oxygen evolution reaction - OER, and hydrogen evolution reaction - HER), which are important in several technological processes, such as water electrolysis, fuel cells, batteries and sensors ${ }^{1,10-17}$. HER and OER are directly related to the demand for sustainable clean energy and concerns about climate change and global warming.

*e-mail: lsenna@uerj.br
The OER is involved in many conversion processes and energy storage ${ }^{14}$. Although noble metals, such as $\mathrm{Pt}, \mathrm{Au}, \mathrm{Ag}$, $\mathrm{Ru}$ and $\mathrm{Ir}$, are generally used as electrodes for OER, they have high cost and low stability in alkaline medium ${ }^{10-12}$. Therefore, there is a growing demand to replace these metals by alternative catalysts with low cost and similar performance ${ }^{15,16,18}$. Transition metal oxides, such as Ni, Co, V, $\mathrm{Fe}$, as well as $\mathrm{Sn}$ oxides, present electrocatalytic properties, which make them attractive alternatives electrodes for several reactions, including $\mathrm{OER}^{16}$. Among them, the $\mathrm{Co}_{3} \mathrm{O}_{4}$ is an interesting material to be used for this purpose ${ }^{11,12}$.

The insertion of the $\mathrm{Ni}$ in the $\mathrm{Co}_{3} \mathrm{O}_{4}$ structure forms the mixed oxide $\mathrm{NiCO}_{2} \mathrm{O}_{4}$, nickel cobaltite. It causes changes in the thermal behavior, geometric structure and electronic properties, when compared to the original material $\left(\mathrm{Co}_{3} \mathrm{O}_{4}\right)$, resulting in an increase in the electrocatalytic activity of this material for $\mathrm{OER}^{13}$. The $\mathrm{NiCo}_{2} \mathrm{O}_{4}$ is not aggressive to the environment and may have different nanostructures. This mixed oxide presents stability, activity and low cost, being active in the oxygen evolution and reduction reactions, in alkaline medium ${ }^{18,19}$ and also in the electro-oxidation of amines and alcohols ${ }^{16}$.

Even though the production of films in neutral media is encouraged ${ }^{1}$, generally, Ni-Co mixed oxides are electrodeposited using alkaline solutions and studies using others $\mathrm{pH}$ ranges 
are scarcely reported ${ }^{1,5,20-22}$. Therefore, this paper proposes the production of nanostructured $\mathrm{Ni}$-Co oxide coatings on steel substrate from neutral and alkaline citrate-based medium, using chronopotenciometric methods. The coatings were characterized morphological and structurally to identify the Ni-Co oxide phase formation, while the electrocatalytic evaluation of these coatings for OER was performed in alkaline medium.

\section{Experimental Procedures}

\section{$2.1 \mathrm{Ni}$-Co oxide production}

The Ni-Co oxides films were produced on AISI 1020 carbon steel substrate using chronopotentiometry, as shown in Table 1. The conditions applied in each experiment were based on previously published results ${ }^{20,21,23}$. A solution containing $0.05 \mathrm{~mol} \mathrm{~L}^{-1} \mathrm{NiSO}_{4} \cdot 6 \mathrm{H}_{2} \mathrm{O}, 0.10 \mathrm{~mol} \mathrm{~L}^{-1} \mathrm{CoSO}_{4} \cdot 7 \mathrm{H}_{2} \mathrm{O}$ and 0.15 mol L-1 sodium citrate was used to produce the films. The $\mathrm{pH}$ of this solution was adjusted with sodium hydroxide ( $5.0 \mathrm{~mol}$ $\left.\mathrm{L}^{-1}\right)$ or concentrated sulfuric acid to produce the electrolytes denominated Solution 1 ( $\mathrm{pH} 7.5)$ and Solution 2 ( $\mathrm{pH} 10.5)$.

All the experiments used a three-electrode cell, where the steel substrate was the working electrode (exposed area $=2.54 \mathrm{~cm}^{2}$ ), a platinum spiral was the counter electrode and saturated mercurous sulfate (ESS) was the reference electrode. The steel electrodes were previously polished with sandpaper (grain size 100-600 mesh) and then degreased with sodium lauril sulfate solution. The counter electrode was immersed in $20 \% \mathrm{v} / \mathrm{v} \mathrm{HNO}_{3}$ solution for $1 \mathrm{~min}$ to remove any oxide layer that could be present. Both electrodes were cleaned with water and alcohol, and finally dried before immersion in the electrolytic solutions.

\subsection{Characterization of coatings}

$\mathrm{X}$-rays diffractograms (XRD) of the coatings were obtained using a diffractometer (RIGAKU D/MAX - 2200/PC) with a copper source at $40 \mathrm{kV}$. The $2 \theta$ ranged from $10^{\circ}$ to $120^{\circ}$ at a scanning rate of $0.050^{\circ} \mathrm{s}^{-1}$. The diffractogram lines of the deposited Ni-Co oxides were fitted by a Gaussian equation to obtain their $2 \theta$ values, which were used to calculate the $d$ (h $\mathrm{k}$ ) parameters of the diffraction lines. The same fitting was used to determinate the full width at half maximum (FWHM) and the height of the most representative line. As the FWHM of the X-ray diffraction line is related to the apparent size of the particle ${ }^{24}$, this parameter was used to evaluate the size of the crystallites, using Scherrer Equation (1):

$$
C_{R}=\frac{\Delta W}{A . t}
$$

where $d_{p}$ is the crystallite size, $\mathrm{k}$ is a constant related to the type of the crystal structure, $\lambda$ is the wavelength of the incident radiation ( $\mathrm{nm}$ ), and $\beta$ is the FWHM.

The morphological analysis was performed using a scanning electron microscope JEOL JSM-6510LV. The analysis was carried out at high vacuum and using secondary electron mode, at a voltage of $20 \mathrm{kV}$. The images were acquired at different magnifications.

The quantitative analysis of the chemical composition of the produced samples was performed using energy dispersive spectrometry (EDS) system coupled to a TM3000, with magnification of $100 \mathrm{x}$, in three different regions.

Raman spectroscopy (LRS) analyses were obtained using an instrument LabRam HR800 UV (Horiba/Jobin Yvon), with a He-Ne laser $(\lambda=632.84 \mathrm{~nm}), \mathrm{CCD}$ detector cooled at $-70^{\circ} \mathrm{C}$ and a confocal microscope Olympus BX41. The analysis were performed in 2 or 3 areas of the electrode, at room temperature. The spectra were obtained in the range of $400-1800 \mathrm{~cm}^{-1}$ without a filter, and lens with a magnification of $10 \mathrm{x}, 50 \mathrm{x}$ and $100 \mathrm{x}$.

The performance of the coatings as an electrocatalyst for the OER process was evaluated in $\mathrm{KOH} 1 \mathrm{~mol} \mathrm{~L}^{-1}$ using anodic polarization curves and electrochemical impedance spectroscopy (EIS). The electrolytic cell used in these experiments was composed by the oxide film/substrate system as the working electrode, a platinum spiral as the counter electrode and the $\mathrm{Hg} / \mathrm{HgO}$ as the working electrode. The same RDE system (AUTOLAB RDE-2), coupled to the potentiostat/galvanostat PGSTAT $302 \mathrm{~N}$, was used in these experiments, with a stirring speed of $100 \mathrm{rpm}$.

First, the ability of the coatings as a catalyst in the studied medium was verified using anodic polarization curves. These curves were achieved after the stabilization of the system in the open circuit potential for $600 \mathrm{~s}$, varying from the open circuit potential (OCP) to $2.0 \mathrm{~V}_{\mathrm{Hg} / \mathrm{HgO}}$, with a scan speed of $1 \mathrm{mV} \mathrm{s}^{-1}$.

The results of the polarization curves were used to select the potential to be applied for the EIS analysis. Therefore, these experiments were performed in an anodic potential,

Table 1. Experimental conditions used to produce the Ni:Co oxide coatings

\begin{tabular}{|c|c|c|}
\hline Experiment no. & $\begin{array}{l}\text { Cathodic Chronopotentiometry } \\
\text { I }\left(\mathrm{A} \mathrm{m}^{-2}\right)\end{array}$ & $\begin{array}{l}\text { Anodic Chronopotentiometry } \\
\qquad \mathrm{I}\left(\mathrm{A} \mathrm{m}^{-2}\right)\end{array}$ \\
\hline 1 & $\begin{array}{c}I=20 \\
t=3226 s\end{array}$ & - \\
\hline 2 & $\begin{array}{c}I=20 \\
t=3226 s\end{array}$ & $\begin{array}{l}I=17.96 \\
t=7190 \mathrm{~s}\end{array}$ \\
\hline 3 & $\begin{array}{c}I=20 \\
t=3226 s\end{array}$ & $\begin{array}{l}I=47.15 \\
t=2736 s\end{array}$ \\
\hline
\end{tabular}


different from the $\mathrm{OPC}$, using a frequency range from $10^{5}$ to $10^{-3} \mathrm{~Hz}$ and amplitude of $10 \mathrm{mV}$.

\section{Results and Discussion}

As shown in Table 1, all the experiments were performed with a previous reduction of the metallic ions (Co (II) and $\mathrm{Ni}$ (II)) because previous studies ${ }^{25}$, indicated that the direct oxidation of species on the electrode surface was not possible, under the conditions used in the present experiments. All the electrochemical experiments were conducted in order to find the appropriate conditions for the electrodeposition of Ni-Co (1: 2 ratio) mixed oxide. The coatings produced using Solutions 1 and 2 (pH 7.5 and 10.5, respectively) were adherent to the substrate, independent of the conditions used. These coatings were stable, homogeneous, presenting bright $(\mathrm{pH} 7.5)$ or opaque $(\mathrm{pH} 10.5)$ gray color.

\subsection{Chemical composition of the coatings}

Table 2 presents the chemical composition of the coatings produced under the conditions presented in Table 1, using Solutions $1(\mathrm{pH} \mathrm{7.5)}$ and $2(\mathrm{pH} 10.5)$.

The chemical characterization results show that the coatings producing using Solution 1 (Coatings 1, 2 and 3, for those produced under the conditions of Experiments 1, 2 and 3 , respectively) presented approximately 1:4 Ni:Co ratio, independent of the experiment conditions uses. On the other hand, there is an increase in the $\mathrm{Ni}$ content of the coatings produced using Solution 2, mainly those deposited under the conditions of Experiments 2 and 3 (corresponding to Coatings 2' and 3'of Table 1), where Ni:Co ratios 1:1.5 and 1:1 were obtained, respectively. The anodic electrodeposition of mixed $\mathrm{Ni}$-Co oxide is considered more effective under the conditions where low valence metallic ions, $\mathrm{Co}$ (II) and $\mathrm{Ni}$ (II), are stable in solution, while the high valence metallic ions, $\mathrm{Co}$ (III), Co (IV), $\mathrm{Ni}$ (III) and $\mathrm{Ni}$ (IV), are in the form of insoluble oxides, which is enhanced at more alkaline $\mathrm{pH}$ values $^{1}$. Therefore, the present results show that it may not be able to produce stoichiometric or near stoichiometric Ni-Co oxide using Solution 1 ( $\mathrm{pH} 7.5$ ).

There is not a concensus in literature concerning the relationship between the stoichiometry of the $\mathrm{NiCo}_{2} \mathrm{O}_{4}$ spinel and its properties as a catalyst for the oxygen evolution reaction. Although it is considered that the stoichiometric spinel structure presents the best electrocatalytic performance ${ }^{26,27}$, $\mathrm{Hu}$, Lee and $\mathrm{Wen}^{28}$ showed that non-stoichiometric structures containing mixture of different metallic ions could also act as catalyst materials, because the non-stoichiometric structures may enhance the access for the electron transfer process and the $\mathrm{H}^{+} / \mathrm{OH}^{-}$exchange. Therefore, whatever their stoichiometry, these oxides attract interest because of its electrochemical properties, complex chemical compositions and synergistic effects arising from these interactions ${ }^{29}$.

\subsection{Microstructural characterization of the coatings}

The diffractograms of the coatings produced on steel substrate using the experiments described in Table 1 are presented in Figure 1. It is known that electrolytically obtained materials usually consist of small size crystallite, non-uniform in composition, which present a considerable distortion of the crystal lattice. This distortion is originated during the formation of the non-equilibrium phases at the cathode (or anode), which occurs at high overpotential values. It causes several problems when these materials are analyzed using traditional X-ray examination because, in some cases, non-cataloged crystalline phases can be obtained $^{30,31}$. In addition, the phases present in the deposited material can be only partially revealed ${ }^{32}$. Table 3 presents the values of $d(\mathrm{~h} \mathrm{k} \mathrm{l)}$ for all possible phases present on the coatings produced from these experiments. The diffraction peaks are relatively intense indicating the formation of reasonably crystalline phases.

In the majority of the diffractograms shown in Figure 1, the most intense diffraction peak can be associated with the Fe substrate (110) at $2 \theta \approx 44.6^{\circ}$ (PDF\#06-0696) and to the crystalline structure of the mixed oxide $\mathrm{NiCo}_{2} \mathrm{O}_{4}(400)$, also at $\approx 44.6^{\circ}$ (PDF\#20-0781), in cubic structure. It means that the $\mathrm{NiCo}_{2} \mathrm{O}_{4}$ peak at this $2 \theta$ value could not be appropriately noted in these diffractograms. The correspondents $d$ values for both Fe substrate (110) and $\mathrm{NiCo}_{2} \mathrm{O}_{4}(400)$ are shown in Table 3, for comparison. Moreover, it is possible to note that the diffractograms presented in Figure 1 depend on both the solution and the experiment used to prepare the oxide film.

As suggested by the diffractograms, the coatings produced using Solution 1, at pH 7.5 (Figure 1A), present a mixture of microstructural phases. Thus, it is possible to observe well defined peaks at $2 \theta \approx 41.47^{\circ}, 44.53^{\circ}$ and a low intensity peak at 47.28 $8^{033-35}$, corresponding, respectively, to the planes (200), (140) and (131) of CoOOH (PDF\#26-480), with an orthorhombic structure. There are also peaks related to the mixed oxide $\mathrm{NiCo}_{2} \mathrm{O}_{4}$ at $2 \theta \approx 44.53^{\circ}, 64.87^{\circ}$ and $76.00^{\circ}$, corresponding, respectively, to the planes (400), (440) and (622), with a cubic structure (PDF\#10-0188). Additionally,

Table 2. EDS results for the coatings produced using Solutions 1 and 2

\begin{tabular}{ccccccc}
\hline \multirow{2}{*}{ Experiment no. } & \multicolumn{3}{c}{ Solution 1 } & \multicolumn{3}{c}{ Solution 2 } \\
\cline { 2 - 7 } & Wt.\% Ni & Wt.\% Co & Ratio & Wt.\% Ni & Wt.\% Co & Ratio \\
\hline 1 & 20.45 & 79.55 & $1: 4$ & 22.48 & 77.52 & $1: 3$ \\
2 & 23.32 & 76.48 & $1: 3.5$ & 40.16 & 59.84 & $1: 1.5$ \\
3 & 21.94 & 78.06 & $1: 4$ & 53.96 & 46.04 & $1: 1$ \\
\hline
\end{tabular}



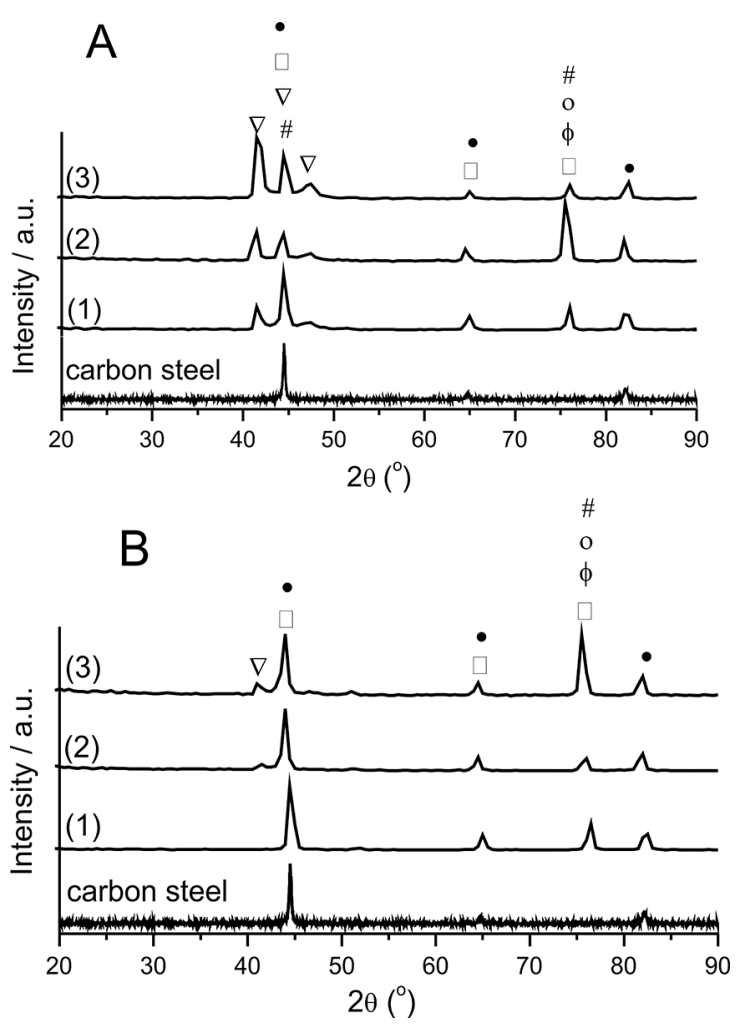

Figure 1. XRD patterns of coatings obtained using Solution 1 (A) and Solution 2 (B) under the conditions described in Table 1: (1) Experiment 1; (2) Experiment 2; (3) Experiment 3. Legend: $\bullet$ Fe; $\phi \mathrm{Co} ; \circ \mathrm{Ni}$ \# NiCo alloy; $\square \mathrm{NiCo}_{2} \mathrm{O}_{4} ; \nabla \mathrm{CoOOH}$

it is possible to observe that the highest diffraction peak of the film produced under the condition of Experiment 2 (Coating 2) is shifted to $2 \theta=75.06^{\circ}$, which can be related to metallic Ni, Co or Ni-Co alloy species ${ }^{36-38}$, as shown in Table 3. Moreover, the diffraction peak at $\sim 44.40^{\circ}$ can also be related to a Ni-Co alloy phase ${ }^{36-38}$. These results suggest that the production of metallic coating using the conditions of Experiment 2 cannot be discarded.

Although the same diffraction peaks were observed for the coatings produced using, Solution $2(\mathrm{pH}=10.5)$, as shown in Figure 1B, the intensity of the $\mathrm{CoOOH}$ peaks decreased significantly. Basically, these coatings present well defined $\mathrm{NiCo}_{2} \mathrm{O}_{4}$ phase, as suggested by their stoichiometric relationship shown in Table 2. The literature confirms the presence of $\mathrm{NiCo}_{2} \mathrm{O}_{4}$ spinel type mixed oxide associated with peaks at $2 \theta \approx 44.36^{\circ}$ and $75.94^{01,20,21,39,40}$, which are near of the $2 \theta$ values obtained in the present work.

It is interesting to note the presence of $\mathrm{NiCo}_{2} \mathrm{O}_{4}$ and/or $\mathrm{CoOOH}$ phases in the coatings produced using only cathodic chronopotentiometry (Experiment 1 of Table 1), independent of the solution $\mathrm{pH}$ used. This result can be related to the metallic oxide and hydroxides that were produced on the electrode surface during metal deposition process, due to the interface alkalization caused by the water and $\mathrm{O}_{2}$ reduction reactions ${ }^{41,42}$. The further anodic chronopotentiometric procedures (Experiments 2 and 3) may have favored the deposition of $\mathrm{CoOOH}$ on the electrode surface when Solution 1 ( $\mathrm{pH} 7.5$ ) was used. This result can be related to the chemical analysis shown in Table 2, in which the Co content in these coatings was about four times higher than the Ni content.

Even though, the diffractograms obtained for the coatings produced using all the experiments conditions presented in Table 1, independent of the solution $\mathrm{pH}$ used, indicated the formation of the mixed Ni-Co oxide (1:2). The average particle diameter $\left(\mathrm{d}_{\mathrm{p}}\right)$, calculated from Equation (1) using the peak at $2 \theta \approx 76.00$ was $15 \mathrm{~nm}$ and $17 \mathrm{~nm}$, for the coatings produced using Solutions 1 and 2, respectively. These results show that nanometric grains were obtained under the deposition conditions used in this work.

The formation of $\mathrm{NiCo}_{2} \mathrm{O}_{4}$ phase in the electrodeposited films was confirmed using Raman spectroscopy (LRS), as shown in Figure 2. This technique allows the detection of different phases of the material by the vibration modes of the molecules ${ }^{43}$. The results obtained from the deposited films were compared with the bulk oxide $1 \mathrm{Ni}: 2 \mathrm{Co}$ spectrum. The bands at 465, 551 and $655 \mathrm{~cm}^{-1}$ are strongly associated with $\mathrm{NiCo}_{2} \mathrm{O}_{4}^{44,45}$. In addition, a band close at $185 \mathrm{~cm}^{-1}$ was observed in spectra for the nickel cobalt-containing mass oxide. The bands $185,465,551$ and $655 \mathrm{~cm}^{-1}$ are related to the vibrational modes $\mathrm{F}_{2 \mathrm{~g}}, \mathrm{E}_{\mathrm{g}}, \mathrm{F}_{2 \mathrm{~g}}$ and $\mathrm{A}_{1 \mathrm{~g}}$, respectively ${ }^{46-48}$.

Table 3. $d$ (h k 1) values for the coatings produced using Solutions 1 and 2

\begin{tabular}{|c|c|c|c|c|c|c|}
\hline \multirow{2}{*}{$\begin{array}{c}\text { Average } \\
\text { observed } 2 \Theta \\
\text { values }\end{array}$} & \multicolumn{6}{|c|}{$d(\mathrm{~h} \mathrm{k} \mathrm{1)}$} \\
\hline & $\begin{array}{l}\text { Average } \\
\text { Observed values }\end{array}$ & AISI $1020^{\mathrm{a}}$ & $\mathrm{Co}^{\mathrm{b}, \mathrm{c}}$ & $\mathrm{COOH}^{\mathrm{d}}$ & $\mathrm{Ni}^{\mathrm{e}}$ & $\mathrm{NiCo}_{2} \mathrm{O}_{4}{ }^{\mathrm{f}}$ \\
\hline 41.72 & 2.162 & & & $2.177(200)$ & & \\
\hline 44.26 & 2.044 & $2.027(110)$ & & $2.067(200)$ & $2.034(111)$ & $2.029(400)$ \\
\hline 47.44 & 1.914 & & $1.910(101)$ & $1.895(131)$ & & \\
\hline 64.77 & 1.438 & $1.433(200)$ & & & & $1.434(440)$ \\
\hline 75.30 & 1.260 & & $1.250(110)$ & & $1.260(220)$ & \\
\hline 76.22 & 1.248 & & $1.250(110)$ & & $1.260(220)$ & $1.230(622)$ \\
\hline 82.23 & 1.171 & $1.170(211)$ & & & & \\
\hline
\end{tabular}


A
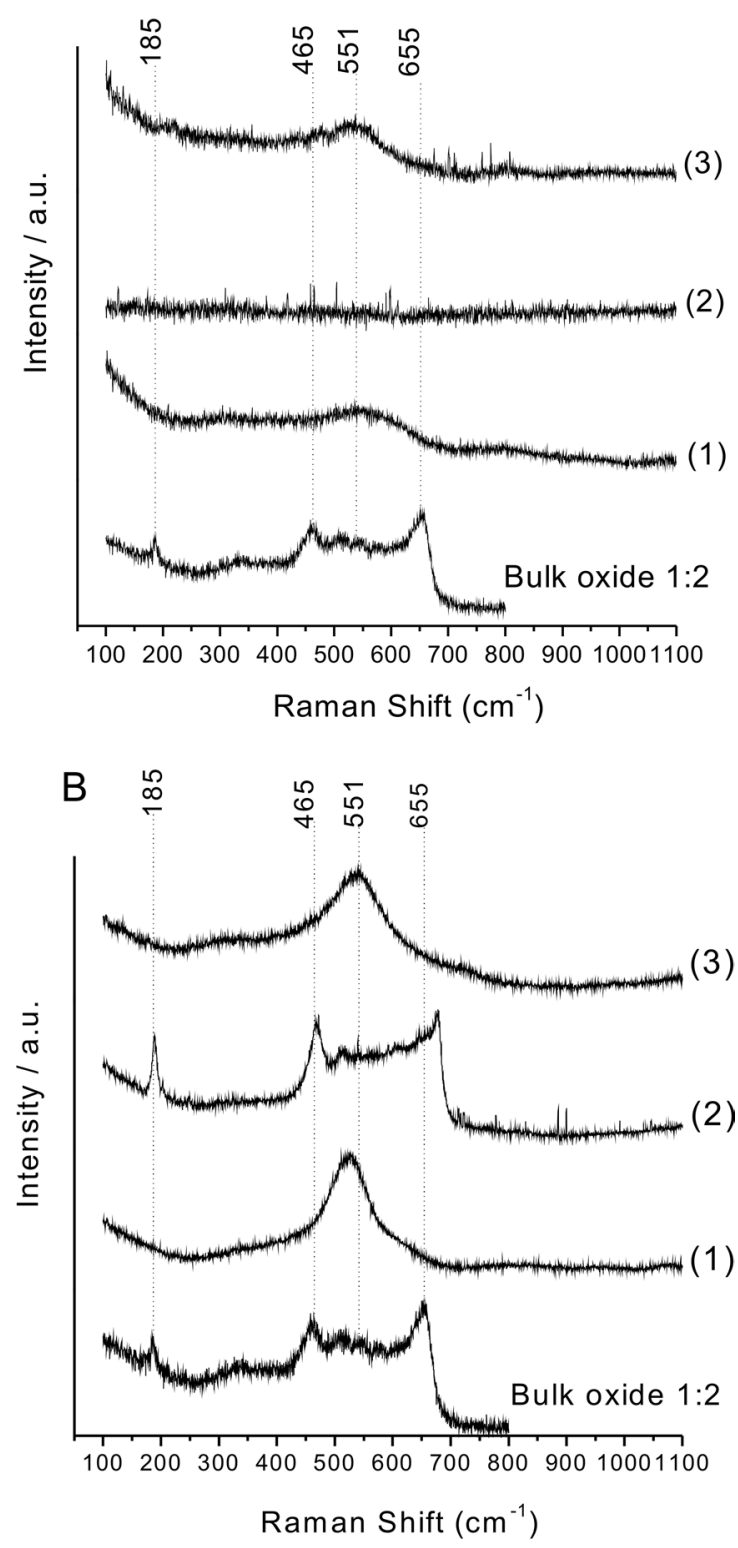

Figure 2. Raman spectra of the coatings obtained using Solution 1 (A) and Solution 2 (B) under the conditions described in Table 1: (1) Experiment 1; (2) Experiment 2; (3) Experiment 3.

Independent of the solution used, the deposited coatings present bands in the region between 465 and $655 \mathrm{~cm}^{-1}$, which are also present in the bulk mixed oxide sample. However, both the solution $\mathrm{pH}$ and the experimental condition (Table 1) used, affected directly the intensity of these bands.

Figure $2 \mathrm{~A}$ presents the results concerning the coatings producing from Solution $1(\mathrm{pH} 7.5)$. As the intensity and width of the LRS bands are set from the thickness, defects and intrinsic characteristics of the vibration mode of the coatings ${ }^{5,43,44}$, the Raman results for coatings produced under these conditions may indicate the formation of thin films. Compared to the bulk mixed oxide sample, the coatings produced under the conditions of Experiments 1 (Cathodic chronopotenciometry) and 3 (Cathodic chronopotenciometry + Anodic chronopotenciometry II) presented only a large and low intensity band with a maximum at approximately $551 \mathrm{~cm}^{-1}$. Although these results suggest that thin coatings were produced under these conditions, the Raman experiments confirm the XRD analysis that the films presented the $\mathrm{NiCo}_{2} \mathrm{O}_{4}$ phase.

On the other hand, the Raman spectrum of the coatings obtained using Solution 1 , under the conditions of Experiment 2 (Cathodic chronopotenciometry + Anodic chronopotenciometry I), does not present bands and the LRS spectrum is a straight line with intensity close to zero. When this result is compared to those obtained in XRD analysis, it is possible to suggest that a metallic coating was obtained, instead of an oxide layer. As the production of high valence metallic Ni-Co oxides using neutral medium is achieved only at more positive potential values ${ }^{1}$, it is probable that the current density used in the anodization process of Experiment 2 was not enough to reach the potential needed to produce an oxide layer on the coating surface. Therefore, this coating has been discarded and was not evaluated morphologically and electrochemically.

The LRS spectra of the coatings obtained using Solution 2 ( $\mathrm{pH} 10.5$ ) is presented in Figure 2B. All the bands are intense, suggesting that thicker coatings were produced under these conditions. Bands strongly associated to the presence of the $\mathrm{NiCo}_{2} \mathrm{O}_{4}$ mixed oxide $\left(185,465,551 \text { and } 655 \mathrm{~cm}^{-1}\right)^{44,45}$ can be observed for the coatings produced under the conditions of Experiment 2 (Cathodic chronopotenciometry + Anodic chronopotenciometry I). A band at $551 \mathrm{~cm}^{-1}$ is also verified for the coatings produced under the conditions of Experiment 3 (Cathodic chronopotenciometry + Anodic chronopotenciometry II). On the other hand, the coating produced under the conditions of Experiment 1 (Cathodic chronopotenciometry) presented only a well-defined band at approximately $550 \mathrm{~cm}^{-1}$, which can be associated with $\mathrm{NiCo}_{2} \mathrm{O}_{4}^{44,45}$. Therefore, Ni-Co mixed oxide may have been formed in these coatings when produced using Solution 2.

\subsection{Morphological characterization of the coatings}

Ion transfer and conductivity are dependent on the surface structures and the morphology of the films. Therefore, Figure 3 shows the SEM morphological characterization of the coatings produced under the experimental conditions presented in Table 1, using Solution 1 (pH 7.5: Figures 3A and 3D, for Experiments 1 and 3, respectively) and Solution 2 ( $\mathrm{pH}$ 10.5: Figures 3B, 3C and 3E, for Experiments 1, 2 and 3 , respectively). It is possible to note that, even though the XRD and LRS results indicated the presence of nickel cobaltite, the different conditions used to produce the coatings resulted in different morphologies. 

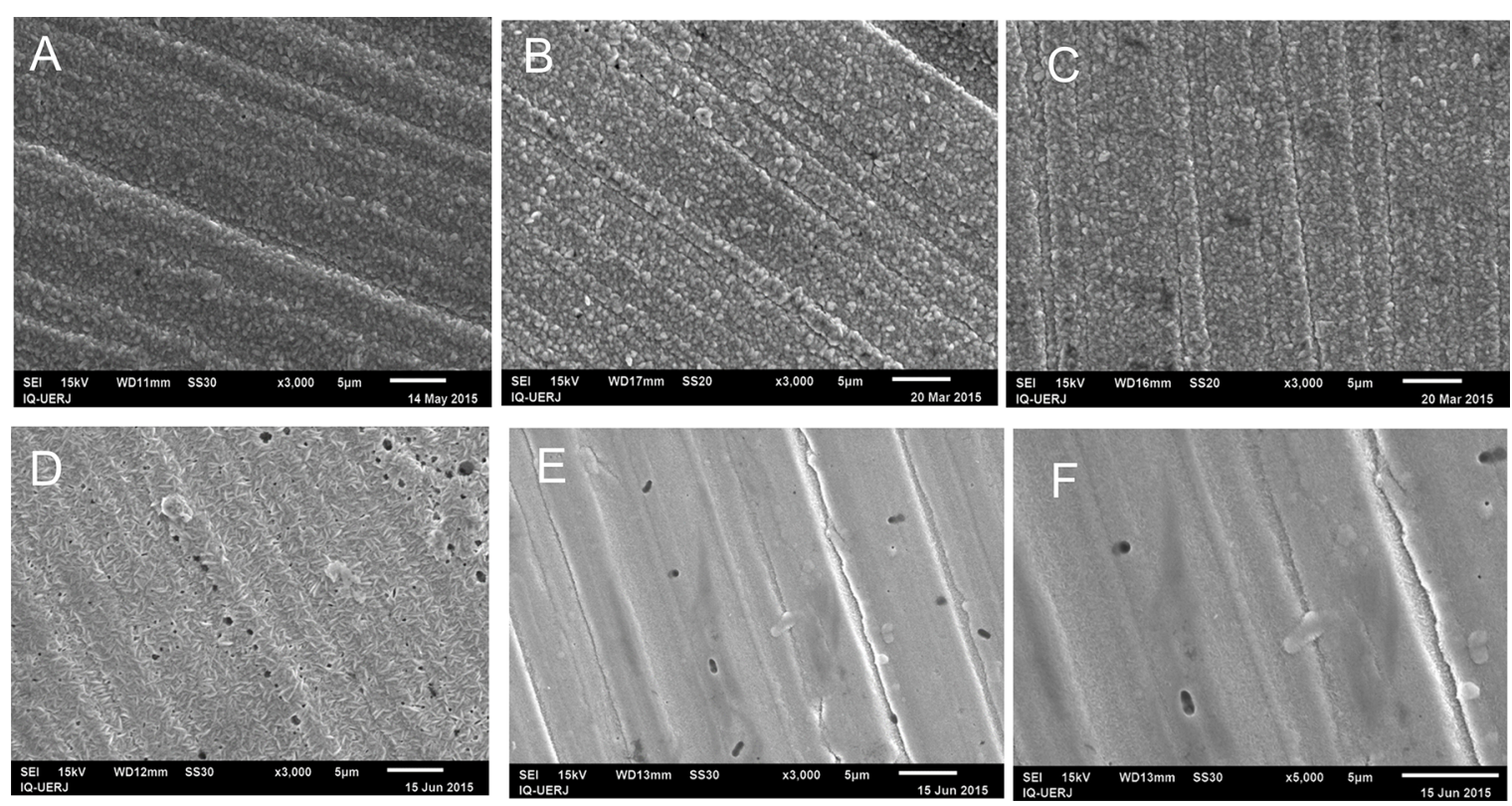

Figure 3. SEM morphological characterization of the coatings produced using Solution 1 (A, D) and Solution 2 (B, C, E) under the conditions described in Table 1: (A, B) Experiment 1; (C) Experiment 2; (D, E) Experiment 3. (F) Magnification of Figure 3E

Both coatings produced using Solutions 1 (Figure $3 \mathrm{~A}$ ) and 2 (Figure 3B), under the conditions of Experiment 1 (Cathodic chronopotenciometry), presented small, coarse and irregular grains, probably related to the cathodic deposition of the alloys form a bath without surfactant agents ${ }^{49,50}$. Moreover, hydroxide ions are also produced in the reduction of $\mathrm{Co}$ (II) and $\mathrm{Ni}$ (II) ions due to the dissociation of their complexes with ligands containing $\beta$-hydroxyl groups, like citrate ${ }^{51}$. Therefore, intermediate components, like $\mathrm{NiOH}^{+}$or $\mathrm{CoOH}^{+}$ can adsorb on the growing active sites of the surface during the deposition process, decreasing the grain growth ${ }^{49,52}$ and contributing to their irregular appearance. Cracks and small pores can also be observed in both coatings.

The coatings submitted to Experiments 2 and 3 (Cathodic chronopotenciometry + Anodic chronopotenciometry I and Cathodic chronopotenciometry + Anodic chronopotenciometry II, respectively) presented different morphologies depending on the solution and current density used. In these experiments, the initial cathodic deposition step produced Co-Ni alloy coatings, likely containing the intermediate components earlier mentioned. This coating can be anodized in the anodic step, producing high valence metallic Ni-Co oxides, depending on the solution $\mathrm{pH}$ and the current density used ${ }^{1}$.

As shown earlier, it was not possible to produce Ni-Co oxides under the conditions of Experiment 2, using Solution 1 $(\mathrm{pH}=7.5)$. However, Figure $3 \mathrm{C}$ shows that the surface morphology of the Ni-Co oxide coating produced under the conditions of Experiment 2 (anodic current density = $17.96 \mathrm{~A} \mathrm{~m}^{-2}$ ), using Solution 2 (Coating 2'), was similar to that observed in Figure 3B (Coating 1'), although presenting smaller grains and several cracks.
When the anodic current density of $47.15 \mathrm{~A} \mathrm{~m}^{-2}$ was applied (Experiment 3 ), the coating produced using Solution 1 (Coating 3) showed a porous needle like structure on its surface (Figure 3D). This structure can be related to the presence of $\mathrm{CoOOH}$ on the surface of the film $\mathrm{m}^{33}$, confirming the XRD result shown in Figure 1A. On the other hand, the grain size of the coating produced using Solution 2 (Coating 3', presented in Figure 3E) seems to be smaller than those earlier mentioned in this work. Moreover, there are cracks on its surface. Under this layer, however, it is possible to observe the same needle-shaped grains verified in Figure 3D, as can be seen in the magnification of this figure (Figure 3F). Although this coating presents Ni:Co ratio $=1: 1$ (Table 2), its XRD also shows the presence of the $\mathrm{CoOOH}$ phase.

\subsection{Electrocatalytical evaluation of the coatings}

The produced Ni-Co oxide coatings were evaluated for the oxygen evolution reaction (OER) in alkaline medium. The anodic polarization curves for the coatings produced using Solutions 1 and 2, in $\mathrm{KOH} 1 \mathrm{~mol} \mathrm{~L}^{-1}$, are presented in Figures $4 \mathrm{~A}$ and $4 \mathrm{~B}$, respectively. The aim of this experiment was to verify whether the presence of the $\mathrm{Ni}$-Co oxide layer enhanced the OER process by decreasing its potential in the studied medium.

It is possible to verify that all the coatings produced using Solution 1 (Figure 4A) presented very low anodic current variation. This result indicates that these coatings do not show high catalytic activity for OER when produced using a solution at $\mathrm{pH}$ 7.5. The oxidation, at high extent, of Co (II) and $\mathrm{Ni}$ (II) ions to high valence oxides in neutral solution requires very high potential values $\left(>1.5 \mathrm{~V}_{\mathrm{Hg} / \mathrm{HgO}}\right)^{1}$. 

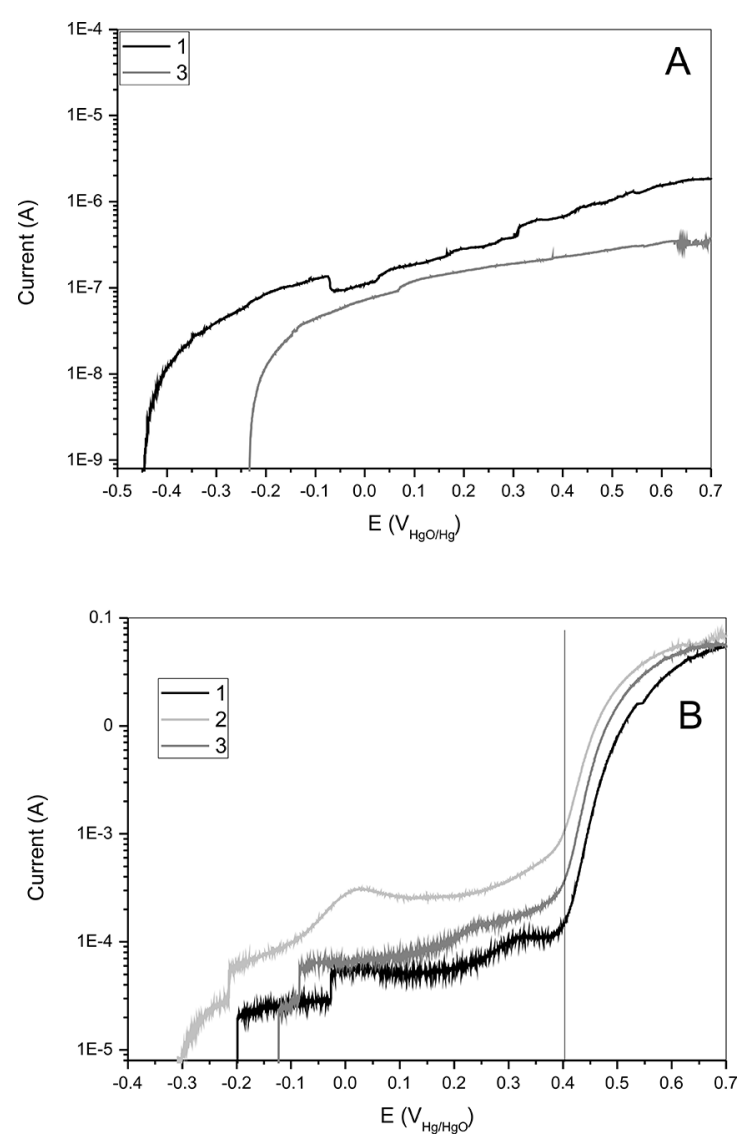

Figure 4. Polarization curves of the coatings produced using Solution 1 (A) and Solution 2 (B) under the conditions described in Table 1: (1) Experiment 1; (2) Experiment 2; (3) Experiment 3. Electrolyte: $\mathrm{KOH} 1 \mathrm{~mol} \mathrm{~L}^{-1}$; scan rate $=1 \mathrm{mV} \mathrm{s}^{-1}$

Although the XRD results indicated the presence of Ni-Co oxides and/or $\mathrm{CoOOH}$ in the coatings produced under the condition of Experiments 1 and 3, the Raman spectroscopy suggested that Coatings 1 and 3 were very thin. Therefore, it is possible that, in the present work, the amount of high valence oxides produced using Solution 1 were not enough to enhance the oxygen evolution process.

The presence of alkaline medium promotes the formation of the metallic hydroxides, which decreases the potential for the oxidation of $\mathrm{Ni}$ (II) and Co (II) species to high valence oxides $^{1}$. Thus, those coatings produced using Solution 2 (Figure 4B) presented a significant increase in the anodic current at around $0.4 \mathrm{~V}_{\mathrm{Hg} / \mathrm{HgO}}\left(\sim 0.5 \mathrm{~V}_{\mathrm{SHE}}\right)$, due to OER. It means that, independent of the experimental process used, all the coatings produced using Solution 2 show electrocatalytic activity for the studied reaction. However, when the curves are compared at the chosen potential, it is possible to note that those produced under the conditions of Experiments 2 and 3 (Coatings 2' and 3', respectively) presented higher anodic current variation than that obtained using the conditions of Experiment 1 (Coating 1'). As the anodic step presented in
Experiments 2 and 3 enhanced the formation of coatings containing Ni-Co oxides and/or $\mathrm{CoOOH}$, this result suggests that Coatings 2' and 3' may have favored the OER process.

Based on the results of the polarization experiments, only the coatings produced using Solution 2 were evaluated by EIS. This analysis was performed at $0.4 \mathrm{~V}_{\mathrm{Hg} / \mathrm{HgO}}$, which was chosen from the polarization curves presented in Figure 4B. Figure 5 shows the Nyquist diagrams for the coatings produced using Solution 2, as well as the EIS data simulation

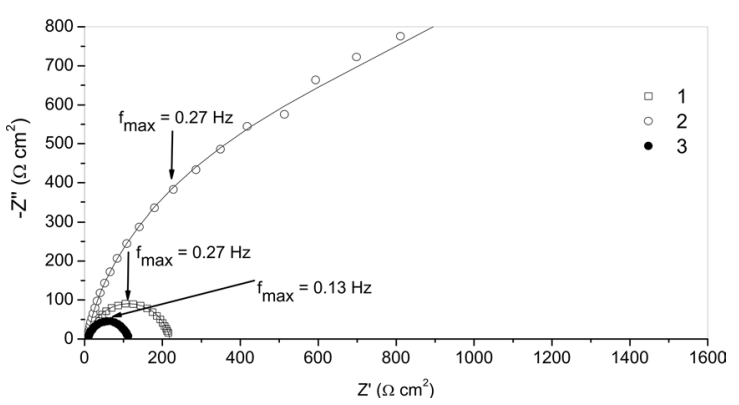

Figure 5. Nyquist diagram of the coatings produced using Solution 2 under the conditions described in Table 1: (1) Experiment 1; (2) Experiment 2; (3) Experiment 3. Electrolyte: $\mathrm{KOH} 1 \mathrm{~mol} \mathrm{~L}^{-1}$.
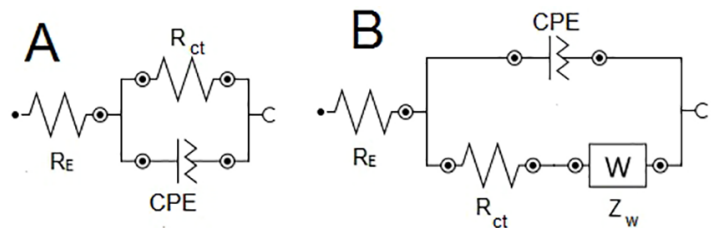

Figure 6. Equivalent circuits used to simulate the EIS data obtained for the coatings produced using Solution 2: (A) Experiments 1 and 3; (B) Experiment 2

using the equivalent electric circuits shown in Figure 6. The values of the simulated parameters are presented in Table 4.

In Figure 5, both coatings produced under the conditions of Experiment 1 (Cathodic chronopotenciometry) and Experiment 3 (Cathodic chronopotenciometry + Anodic chronopotenciometry II) show capacitive loops at high frequency values, which can be related to the double layer processes in the studied solution. The equivalent circuit of Figure 6A was used to simulate the results of Experiments 1 and 3. The diameter of the capacitive loop is related with the $\mathrm{R}_{\mathrm{ct}}$ value of the coating/substrate system in the studied medium $^{53,54}$. Therefore, both Figure 5 and Table 4 affirm that the $\mathrm{R}_{\mathrm{ct}}$ value of Coating $3^{\prime}$ is smaller than that verified for Coating 1'. The present result corroborates those found in the polarization curves (Figure 4B) that Coating 3' presented a higher electrocatalytic activity for the OER than Coating 1'. Both $\mathrm{R}_{\mathrm{ct}}$ values are similar to those found for electrodeposited $\mathrm{Ni}-\mathrm{Co}$ oxide coatings in alkaline medium ${ }^{55}$. In addition, its high $\mathrm{C}_{\mathrm{DL}}$ value suggests that this coating may be studied as a capacitor. 
Table 4. Simulated responses for the EIS data using the equivalent circuits of Figure 6

\begin{tabular}{cccccc}
\hline Experiment & $\mathrm{R}_{\mathrm{E}}(\Omega)$ & $\mathrm{R}_{\mathrm{TC}}\left(\Omega \mathrm{cm}^{2}\right)$ & $\mathrm{N}$ & $\mathrm{EFC}(\mathrm{Mho})$ & $\mathrm{C}_{\mathrm{DL}}\left(\mathrm{mF} \mathrm{cm}^{-2}\right)$ \\
\hline 1 & 2.80 & 211.49 & 0.900 & 0.00764 & 2.85 \\
2 & 2.77 & 962.01 & 0.893 & 0.00291 & 1.16 \\
3 & 2.73 & 105.11 & 0.890 & 0.02300 & 8.98 \\
\hline
\end{tabular}

On the other hand, only a small shoulder can be noted at the higher frequency range, when the Nyquist diagram of the coating produced under the condition of Experiment 2 (Cathodic chronopotenciometry + Anodic chronopotenciometry I). At low frequencies, a straight line is seen, which can be related to the Warburg resistance, as can be noted in the equivalent circuit presented in Figure 6B. This type of Nyquist profile is generally associated with a high performance capacitor ${ }^{56}$ and to porous electrodes ${ }^{21}$. In Table 4, Coating 2' shows a smaller double layer capacitance $\left(\mathrm{C}_{\mathrm{DL}}\right)$ than the other studied coatings and a high $\mathrm{R}_{\mathrm{ct}}$ value for the OER process. In the present work, the presence of a Warburg resistance may indicate that the diffusion of ions into the electrode covered by Coating 2 ' is a limiting process for the OER.

\section{Conclusions}

Ni:Co oxide coatings, with different stoichiometric relationships, were prepared by electrochemical techniques from citrate-based electrolytes at $\mathrm{pH} 7.5$ and 10.5 (Solutions 1 and 2, respectively). Both the solution and the experimental procedures used to prepare the coatings affected directly their characteristics and properties. The use of DRX in association with Raman spectroscopy permitted to discriminate the phases related with $\mathrm{Ni}_{\mathrm{x}} \mathrm{Co}_{2-\mathrm{x}} \mathrm{O}_{4}$ and $\mathrm{Co}_{3} \mathrm{O}_{4}$, deposited on the surface of AISI 1020 carbon steel substrate, and discard the metallic ones. The morphology of the coatings presented small size irregular grains and several holes and cracks.

Although Ni-Co oxides were produced using both solutions, the coatings produced using Solution 1 did not show electrocatalytic activity. On the other hand, the OER process was favored by the coatings produced using Solution 2 mainly that obtained under the conditions of Experiment 3, in which an anodic oxidation step using high current density value was included.

\section{Acknowledgements}

The authors would like to thank the Rio de Janeiro Research Foundation (FAPERJ), the Brazilian National Research Council (CNPq), the State University of Rio de Janeiro (UERJ), and the Prociência Program for financial support. We would like also to thank Antônio Vitor de Castro Braga for technical support, M.Sc. Thiago Correia and Isaac Mallet (LabMEV/UERJ) for the SEM analysis, D.Sc. Rodrigo Bonfim and M.Sc. Adão Gonçalves de Souza (NUCAT/PEQ/COPPE/UFRJ) for the LRS analysis and Mona Andrade (INT) for the EDS analysis.

\section{References}

1. Wu G, Li N, Zhou DR, Mitsuo K, Xu BQ. Anodically electrodeposited $\mathrm{Co}+\mathrm{Ni}$ mixed oxide electrode: preparation and electrocatalytic activity for oxygen evolution in alkaline media. Journal of Solid State Chemistry. 2004;177(10):3682-3692.

2. Casella IG, Contursi M. Cobalt oxide electrodeposition on various electrode substrates from alkaline medium containing Co-gluconate complexes: a comparative voltammetric study. Journal of Solid State Electrochemistry. 2012;16(12):3739-3746.

3. Santana RAC. Otimização do processo de eletrodeposição das ligas Co-Mo E Ni-Co-Mo para mitigar o efeito da corrosão. [Thesis]. Campina Grande: Universidade Federal de Campina Grande; 2007.

4. Wang J, Qiu T, Chen X, Lu Y, Yang W. Hierarchical hollow urchin-like $\mathrm{NiCo}_{2} \mathrm{O}_{4}$ nanomaterial as electrocatalyst for oxygen evolution reaction in alkaline medium. Journal of Power Sources. 2014;268:341-348.

5. Zhang $\mathrm{H}$, Li H, Wang $\mathrm{H}, \mathrm{He} \mathrm{K}$, Wang $\mathrm{S}$, Tang $\mathrm{Y}$, et al. $\mathrm{NiCo}_{2} \mathrm{O}_{4} / \mathrm{N}$-doped graphene as an advanced electrocatalyst for oxygen reduction reaction. Journal of Power Sources. 2015;280:640-648.

6. Zakaria MB, Hu M, Pramanik M, Li C, Tang J, Aldalbahi A, et al. Synthesis of Nanoporous Ni-Co Mixed Oxides by Thermal Decomposition of Metal-Cyanide Coordination Polymers. Chemistry - An Asian Journal. 2015;10(7):1541-1545.

7. RenaudG. Oxide surfaces and metal/oxide interfaces studied by grazing incidence X-ray scattering. Surface Science Reports. 1998;32(1):5-90.

8. Stenger V. Rugosidade superficial de camadas eletrodepositadas de óxido de cobre. [Dissertation]. Florianópolis: Universidade Federal de Santa Catarina; 2008.

9. Bartkowska A, Przestacki D, Chwalczuk T. Microstructure, phase composition and corrosion resistance of $\mathrm{Ni}_{2} \mathrm{O}_{3}$ coatings produced using laser alloying method. Archives of Mechanical Technology and Materials. 2016;36(1):23-29.

10. De Faria LA, Prestat M, Koenig JF, Chartier P, Trasatti S. Surface properties of $\mathrm{Ni}+\mathrm{Co}$ mixed oxides: a study by X-rays, XPS, BET and PZC1. Electrochimica Acta. 1998;44(8-9):1481-1489.

11. Jiang Y, Wu Y, Xie B, Xie Y, Qian Y. Moderate temperature synthesis of nanocrystalline $\mathrm{Co}_{3} \mathrm{O}_{4}$ via gel hydrothermal oxidation. Materials Chemistry and Physics. 2002;74(2):234-237.

12. Yang Y, Liu R, Huang K, Wang L, Liu S, Zeng W. Preparation and electrochemical performance of nanosized $\mathrm{Co}_{3} \mathrm{O}_{4}$ via hydrothermal method. Transactions of Nonferrous Metals Society of China. 2007;17(6):1334-1338.

13. Rashkova V, Kitova S, Konstantinov I, Vitanov T. Vacuum evaporated thin films of mixed cobalt and nickel oxides as electrocatalyst for oxygen evolution and reduction. Electrochimica Acta. 2002;47(10):1555-1560. 
14. Wang H, Yi H, Chen X, Wang X. Facile synthesis of a nanostructured nickel oxide electrode with outstanding pseudocapacitive properties. Electrochimica Acta. 2013;105:353-361.

15. Bertoncello R, Furlanetto F, Guerriero P, Musiani M. Electrodeposited composite electrode materials: effect of the concentration of the electrocatalytic dispersed phase on the electrode activity. Electrochimica Acta. 1999;44(23):4061-4068.

16. MuñozAG, Staikov G. Electrodeposition of Co on oxide modified p-Si surfaces. Electrochimica Acta. 2006;51(14):2836-2844.

17. Hayes ET, Bellingham BK, Mark HB Jr, Galal A. An amperometric aqueous ethanol sensor based on the electrocatalytic oxidation at a cobalt-nickel oxide electrode. Electrochimica Acta. 1996;41(2):337-344.

18. Mendoza-Huizar LH, Rios-Reyes CH, Rivera M. Cobalt electrodeposition onto highly oriented pyrolytic graphite (HOPG) electrode from ammonium sulfate solutions. Química Nova. 2010;33(5):1109-1113.

19. Marco JF, Gancedo JR, Gracia M, Gautier JL, Ríos E, Berry FJ. Characterization of the Nickel Cobaltite, $\mathrm{NiCo}_{2} \mathrm{O}_{4}$, Prepared by Several Methods: An XRD, XANES, EXAFS, and XPS Study. Journal of Solid State Chemistry. 2000;153(1):74-81.

20. Gupta V, Gupta S, Miura N. Electrochemically synthesized nanocrystalline spinel thin film for high performance supercapacitor. Journal of Power Sources. 2010;195(11):3757-3760.

21. Kandalkar SG, Lee HM, Seo SH, Lee K, Kim CK. Preparation and characterization of the electrodeposited Ni-Co oxide thin films for electrochemical capacitors. Korean Journal of Chemical Engineering. 2011;28(6):1464-1467.

22. Chowdhury AN, Rahim A, Ferdosi YJ, Azam MS, Hossain MM. Cobalt-nickel mixed oxide surface: A promising adsorbent for the removal of PR dye from water. Applied Surface Science. 2010;256(12):3718-3724.

23. Casella IG. Electrodeposition of cobalt oxide films from carbonate solutions containing Co(II)-tartrate complexes. Journal of Electroanalytical Chemistry. 2002;520(1-2):119-125.

24. Cullity BD. Elements of X-Ray Diffraction. $2^{\text {nd }}$ ed. London: Addison-Wesley Publishing; 1978.

25. Garcia JR, César DV, Lago DCB, Senna LF. Estudo voltamétrico do processo de formação de óxidos de $\mathrm{Ni}$ e Co em meio de citrato de sódio. In: XX Congresso Brasileiro de Engenharia Química (COBEQ 2014); 2014 Oct 19-22; Florianópolis, SC, Brazil.

26. King WJ, Tseung ACC. The reduction of oxygen on nickelcobalt oxides - I. The influence of composition and preparation method on the activity of nickel-cobalt oxides. Electrochimica Acta. 1974;19(8):485-491.

27. De Chialvo MRG, Chialvo AC. Oxygen evolution reaction on $\mathrm{Ni}_{\mathrm{x}} \mathrm{Co}_{(3-\mathrm{x})} \mathrm{O}_{4}$ electrodes with spinel structure. Electrochimica Acta. 1993;38(15):2247-2252.

28. Hu CC, Lee YS, Wen TC. The physicochemical/electrochemical properties of binary Ni-Co oxides. Materials Chemistry and Physics. 1997;48(3):246-254.

29. Umeshbabu E, Rajeshkhanna G, Rao GR. Urchin and sheaf-like $\mathrm{NiCo}_{2} \mathrm{O}_{4}$ nanostructures: Synthesis and electrochemical energy storage application. International Journal of Hydrogen Energy. 2014;39(28):15627-15638.
30. Gharahcheshmeh MH, Sohi MH. Electrochemical studies of zinc-cobalt alloy coatings deposited from alkaline baths containing glycine as complexing agent. Journal of Applied Electrochemistry. 2010;40(8):1563-7150.

31. Sienna LF, Achete CA, Hirsch T, Mattos O. Characterisation of PVD TiCN layers by physical and electrochemical methods. Surface Engineering. 2005;21(2):144-150.

32. Vagramyan TA. Electrodeposition of Alloys: Mechanism of Simultaneous Reaction of Metal Ions. Jerusalem: Israel Program of Scientific Translation Ltd; 1970.

33. Jagadale AD, Dubal DP, Lokhande CD. Electrochemical behavior of potentiodynamically deposited cobalt oxyhydroxide $(\mathrm{CoOOH})$ thin films for supercapacitor application. Materials Research Bulletin. 2012;47(3):672-676.

34. Kandalkar SG, Gunjakar JL, Lokhande CD, Joo OS. Synthesis of cobalt oxide interconnected flacks and nano-worms structures using low temperature chemical bath deposition. Journal of Alloys and Compounds. 2009;478(1-2):594-598.

35. Yang J, Liu H, Martens WN, Frost RL. Synthesis and Characterization of Cobalt Hydroxide, Cobalt Oxyhydroxide, and Cobalt Oxide Nanodiscs. The Journal of Physical Chemistry C. 2010;114(1):111-119.

36. Yang Y, Cheng YF. Fabrication of Ni-Co-SiC composite coatings by pulse electrodeposition - Effects of duty cycle and pulse frequency. Surface and Coatings Technology. 2013;216:282288.

37. Yang YF, Wen ZH, Li QG. Electrodeposition of Ni-Co alloy films onto titanium substrate. Rare Metals. 2014;33(4):442-447.

38. Salehi M, Saidi A, Ahmadian M, Raeissi K. Characterization of nanocrystalline nickel-cobalt alloys synthesized by direct and pulse electrodeposition. International Journal of Modern Physics B. 2014;28(06):1450043.

39. NuLi Y, Zhang P, Guo ZP, Liu HK, Yang J. $\mathrm{NiCo}_{2} \mathrm{O}_{4} / \mathrm{C}$ nanocomposite as a highly reversible anode material for lithium-ion batteries. Electrochemical and Solid State Letters. 2008;11(5):A64-A67.

40. Yao X, Zhao C, Kong J, Zhou D, Lu X. Polydopamine-assisted synthesis of hollow $\mathrm{NiCo}_{2} \mathrm{O}_{4}$ nanospheres as high-performance lithium ion battery anodes. RSC Advances. 2014;4(71):3792837933 .

41. Garcia JR, Lago DCB, Senna LF. Electrodeposition of Cobalt Rich Zn-Co alloy Coatings from Citrate Bath. Materials Research. 2014;17(4):947-957.

42. de Lima TG, Rocha BCCA, Braga AVC, do Lago DCB, Luna AS, Senna LF. Response surface modeling and voltammetric evaluation of $\mathrm{Co}$-rich $\mathrm{Cu}$-Co alloy coatings obtained from glycine baths. Surface and Coatings Technology. 2015;276:606-617.

43. Gonçalves ES, Rezende MC, Baldan MR, Ferreira NG. Efeito do tratamento térmico na microestrutura, turbostraticidade e superfície de carbono vítreo reticulado analisado por XPS, espalhamento Raman e voltametria cíclica. Química Nova. 2009;32(1):158-164.

44. Windisch CF, Exarhos GJ, Sharma SK. Influence of temperature and electronic disorder on the Raman spectra of nickel cobalt oxides. Journal of Applied Physics. 2002;92(9):5572-5574. 
45. Calin G, Irimia M, Scarlat C, Purica M, Comanescu F, Iacomi F. Synthesis and characterization of nickel cobalt oxide thin films. In: Semiconductor Conference (CAS), 2010 International; 2010 Oct 11-13; Sinaia, Romania.

46. Liu ZQ, Xiao K, Xu QZ, Li N, Su YZ, Wang HJ, et al. Fabrication of hierarchical flower-like super-structures consisting of porous $\mathrm{NiCo}_{2} \mathrm{O}_{4}$ nanosheets and their electrochemical and magnetic properties. RSC Advances. 2013;3(13):4372-4380.

47. Umeshbabu E, Rajeshkhanna G, Justin P, Rao GR. Synthesis of mesoporous $\mathrm{NiCo}_{2} \mathrm{O}_{4}$-rGO by a solvothermal method for charge storage applications. RSC Advances. 2015;5(82):66657-66666.

48. Umeshbabu E, Rao GR. $\mathrm{NiCo}_{2} \mathrm{O}_{4}$ hexagonal nanoplates anchored on reduced graphene oxide sheets with enhanced electrocatalytic activity and stability for methanol and water oxidation. Electrochimica Acta. 2016;213:717-729.

49. Hassani S, Raeissi K, Golozar MA. Effects of saccharin on the electrodeposition of Ni-Co nanocrystalline coatings. Journal of Applied Electrochemistry. 2008;38(5):689-694.

50. Tebbakh S, Messaoudi Y, Azizi A, Fenineche N, Schmerber G, Dinia A. The influence of saccharin on the electrodeposition and properties of Co-Ni alloy thin films. Transactions of the IMF. 2015;93(4):196-204.
51. Zhou Y, Switzer JA. Growth of cerium(IV) oxide films by the electrochemical generation of base method. Journal of Alloys and Compounds. 1996;237(1-2):1-5.

52. Ma C, Wang SC, Walsh FC. Electrodeposition of nanocrystalline nickel-cobalt binary alloy coatings: a review. Transactions of the IMF. 2015;93(2):104-112.

53. Carvalho LA, Andrade AR, Bueno PR. Espectroscopia de impedância eletroquímica aplicada ao estudo das reações heterogêneas em ânodos dimensionalmente estáveis. Química Nova. 2006;29(4):796-804.

54. Al-Amiery AA, Binti Kassim FA, Kadhum AAH, Mohamad AB. Synthesis and characterization of a novel eco-friendly corrosion inhibition for mild steel in $1 \mathrm{M}$ hydrochloric acid. Scientific Reports. 2016;6:19890.

55. Rosalbino F, Delsante S, Borzone G, Scavino G. Electrocatalytic activity of crystalline Ni-Co-M $(\mathrm{M}=\mathrm{Cr}, \mathrm{Mn}, \mathrm{Cu})$ alloys on the oxygen evolution reaction in an alkaline environment. International Journal of Hydrogen Energy. 2013;38(25):1017010177.

56. Fabregat-Santiago F, Garcia-Belmonte G, Bisquert J, Ferriols NS, Bueno PR, Longo E, et al. Dynamic Processes in the Coloration of $\mathrm{WO}_{3}$ by Lithium Insertion. Journal of Electrochemical Society. 2001;148(7):E302-E309. 